\title{
Comparisons of the Amount of Radiation Exposure Among Medical Personnels in Percutaneous Vertebroplasty
}

\author{
Bum-Suk Yu, Hyo Sang Lee, Dong Ah Shin, Yoon Ha, Keung Nyun Kim, Do Heum Yoon, Seong Yi \\ Department of Neurosurgery, Severance Hospital, Yonsei University College of Medicine, Seoul, Korea
}

\begin{abstract}
Objective: X-ray has been used for visualizing internal lesions despite of its biological hazard. Fluoroscopic technique is essential in the modern spinal interventions due to its simplicity and sharpness. Radiation hazard is often under estimated due to Intangible property and late effect. The purpose of this study was to assess radiation exposure during percutaneous vertebroplasty (PVP) which is one of the most frequently performed spinal interventions. Methods: We performed a prospective analysis of a total of 17 consecutive cases of PVP between January 2012 to august 2012. Sixteen patients were osteoporotic compression fractures. One case underwent PVP for pathological compression fracture. Exposure time was calculated automatically by a fluoroscope. For medical personnel, we put a thermoluminescent dosimeters (TLD) on the midpoint of the sternum inside a body apron and another one on the midpoint of a thyroid protector. For patients, one TLD was placed on the table anterior to patient's neck and another one on the table anterior to the treatment level. All TLDs were sent to the lab immediately after PVP. The cumulative dose recorded for each TLD badge was analyzed. Results: The exposure time per one vertebra was $323.77 \pm 23.96$ seconds, ranging 207.00 to 547.00 seconds. The exposure dose measured on a thyroid protector was $2.97 \pm 0.54 \mathrm{mSv}$, ranging 2.11 to $3.21 \mathrm{mSv}$ in the surgeon, $0.04 \pm 0.11 \mathrm{mSv}$, ranging 0.02 to $0.14 \mathrm{mSv}$ in the assistant surgeon, and $0.11 \pm 0.02 \mathrm{mSv}$, ranging 0.08 to $0.15 \mathrm{mSv}$ in the nurse. The exposure dose measured in the radio-protective apron was $0.20 \pm 0.04 \mathrm{mSv}$, ranging 0.15 to $0.30 \mathrm{mSv}$ in the surgeon, $0.01 \pm 0.005$, ranging 0.005 to $0.03 \mathrm{mSv}$ in the assistant surgeon, and $0.04 \pm 0.01 \mathrm{mSv}$, ranging 0.02 to $0.10 \mathrm{mSv}$ in the nurse. The patient showed $0.44 \pm 0.14 \mathrm{mSv}$, ranging 0.33 to $0.54 \mathrm{mSv}$ in the neck area and 3.97. $0.52 \mathrm{mSv}$, ranging 3.44 to $4.12 \mathrm{mSv}$ in the treated area. Conclusion: The amount of radiation exposure was different among medical personnel in performing PVP. The major contributing factor of this difference is supposed to be the distance from a fluoroscope. In addition to wear proper X-ray protective gears and reduce X-ray shooting time, we can further minimize radiation exposure by standing aside from the fluoroscope.
\end{abstract}

Key Words: Radiation dosage; Radiation risk; Fluoroscopy; Vertebroplasty

$\triangle$ Corresponding Author: Seong Yi, Department of Neurosurgery, Severance Hospital, Yonsei University College of Medicine, 50-1 Yonsei-ro, Seodaemun-gu, Seoul 03722, Korea. Tel: +82-2-2228-2150, Fax: +82-2-393-9979, E-mail: yiseong@yuhs.ac

\section{INTRODUCTION}

X-ray has been used for visualizing internal lesions despite of its biological hazard. Fluoroscopic technique is essential in the modern spinal interventions due to its simplicity and sharpness. Radiation hazard is often under estimated due to intangible property and late effect. However, radiation-induced diseases are real and occurring in forms of leukopenia, anemia, bone marrow failure, aplastic anemia, leukemia, chronic dermatitis, skin cancer, hair loss, ulcers and infertility ${ }^{1)}$. Percutaneous vertebroplasty (PVP) consists of injecting a bone cement into a fractured vertebral body under fluoroscopic guidance. PVP has been typically performed in elderly patients with osteoporotic compression fractures since it first introduction by Galibert et al. in $1984^{2}$. Although recent papers has raised questions about its lont-term effectiveness, PVP is still performed with large number due to its relative simplicity, safeness, and effective procedure ${ }^{3)}$. Furthermore, PVP has been broadened from osteoporotic compression fractures to metastatic spine tumors, nonosteoporotic compression fractures, or screw augmentations. Comparing with pain blocks such as transforaminal selective epidural block, medial branch block and caudal block, PVP consumes more radiation for needle positioning, venogram, and cement injection. Consequently, medical staffs including physicians, assistants, and nurses are significantly and constantly being exposed to unavoidable low dose radiation by fluoroscope. This will be a significant problem especially in pregnant, breastfeeding or childbearing age. The International Commission on Radiological Protection (ICRP) has set an annual maximum allowance for radiation dose. And there are personal radiation exposure limit guidelines. Unfortunately, we can know how much we were irradiated some weeks later after laboratory 
examination. The purpose of this study was to assess radiation exposure of medical staffs and patients in performing PVP, ultimately to provide safety guideline.

\section{MATERIALS AND METHODS}

\section{Subjects}

The study protocol was approved by the Institutional Review Board (IRB). Informed consent was obtained in all patients before PVP. We performed a prospective analysis of a total of 17 consecutive cases of PVP between January 2012 to August 2012. The study included 2 males and 14 females with a mean age of $72.7 \pm 6.1$ years, ranging 56 to 85 years. Sixteen patients were osteoporotic compression fractures. One case underwent PVP for pathological compression fracture. There were 10 thoracic cases and 7 lumbar cases. All patients with osteoporotic compression fractures underwent percutaneous vertebroplasty after more than 2 weeks of conservative care.

\section{Surgical Procedure}

The patient was placed in a prone position on the radiolucent operating table. After skin preparation, the operation field was covered with a disposable skin drape. During the procedure, medical personnel wore lead aprons whereas patients did not. The mobile C-arm fluoroscope was located next to the patient's left side for the practitioner's convenience. A nurse and the $\mathrm{C}$-arm fluoroscope operator were always in proximity to the device. After localizing the lesion with a $\mathrm{C}$-arm fluoroscope (BV pulsera, Philips, Netherlands), a J type bone marrow needle was inserted into the body via the pedicle. Then a venogram

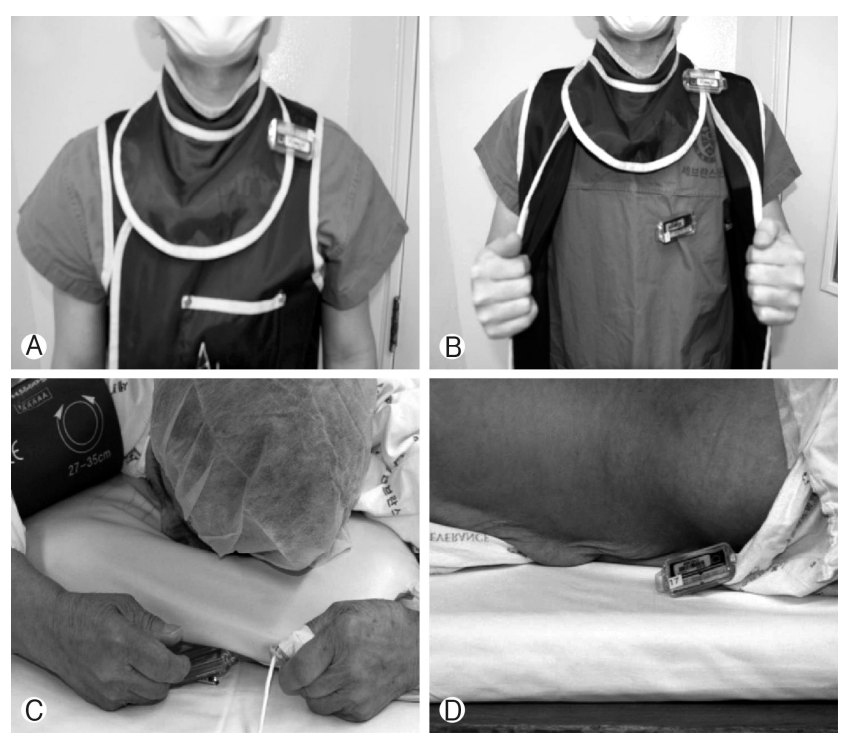

Fig. 1. Dosimeter sites (A: Outside thyroid protector, B: Inside apron, C: Around patient's head, D: Patient's treatment area). was performed. After confirming that the bone cement has sufficiently filled the vertebral body, we waited approximately 5 minutes. Then, the needle was removed.

\section{Assessment of Radiation Exposure}

The thermoluminescent dosimeter (TLD; Panasonic, Osaka, Japan) was used for measuring the individual radiation exposure. A thermoluminescent dosimeter, or TLD, is a type of radiation dosimeter. A TLD measures ionizing radiation exposure by measuring the amount of visible light emitted from a crystal in the detector when the crystal is heated. A total of 8 TLD badges was used for a case. TLD badges were stored in the radiation shielded storage and opened just before each procedure. Medical personnel wore two TLD badges, one on the anterior chest inside the lead apron and on the thyroid outside the lead apron. Patients wore also two TLD badges, on the head and the other on the treatment area (Fig. 1). Each TLD badge was identified by the serial number. Immediately after the procedure, the TLD badges were quickly delivered to at the laboratory (KNDT\&I, Seoul, Korea) for calculating the radiation dose. The total dose of used radiation was obtained by the C-arm. The locations of each TLD badge are shown in Fig. 1. The cumulative dose was divided by the number of augmented levels. The annual permissible number of procedures was calculated based on the mean exposure dose at each location.

\section{Statistical Analysis}

Values are reported as the mean \pm standard deviation. The difference between the patient's treatment area and radiation dosage was analyzed with a Wilcoxon-signed-rank test using SPSS 18.0 (IBM Corporation, Armonk, NY, USA). The dosage and duration of radiation exposure was also analyzed. $p$-values less than 0.05 were considered statistically significant.

\section{RESULTS}

The cumulative total radiation exposure time was 764.77 seconds \pm 105.12 ranging from 450.21 to $1,056.21$ and the mean exposure time per vertebra was 323.77 seconds \pm 23.96 ranging from 207.0 to 547.0. The mean emitted radiation dose from the fluoroscope was $854.50 \mathrm{mSv} \pm 136.20$ ranging from 540.22

Table 1. Emitted dose from the fluoroscope at the thoracic and lumbar levels

\begin{tabular}{lccc}
\hline & Thoracic & Lumbar & $p$-value \\
\hline $\begin{array}{l}\text { Cumulative dose per vertebrae } \\
\text { (mSv) }\end{array}$ & 51.2 & 49 & 0.922 \\
$\begin{array}{l}\text { Fluoroscopy time per vertebrae } \\
(\mathrm{s})\end{array}$ & 355.2 & 278.9 & 0.097 \\
\hline
\end{tabular}


Table 2. Radiation exposure after 17 consecutive procedures in 16 patients

\begin{tabular}{lccccccc}
\hline \multirow{2}{*}{ Dosimeter site } & \multicolumn{2}{c}{ Cumulative radiation dose $(\mathrm{mSv})$} & & \multicolumn{3}{c}{ Radiation dose per vertebrae $(\mathrm{mSv})$} \\
\cline { 2 - 3 } \cline { 6 - 8 } & Surgeon & Assistant surgeon & Nurse & & Surgeon & Assistant surgeon & Nurse \\
\hline Outside thyroid protector & 2.97 & 0.04 & 0.11 & & 0.1747 & 0.0024 & 0.0065 \\
Inside apron & 0.20 & 0.01 & 0.04 & & 0.0118 & 0.0006 & 0.0024 \\
Patient's treatment area & & 3.97 & & & 0.2335 & 0.0259
\end{tabular}

Table 3. International Commission on Radiological Protection (ICRP) recommended annual individual occupational dose limits

\begin{tabular}{|c|c|}
\hline Location & Dose limits \\
\hline $\begin{array}{l}\text { Whole body } \\
\text { (effective dose) }\end{array}$ & $\begin{array}{l}20 \mathrm{mSv} / \text { year average over defined periods } \\
\text { of } 5 \text { years }\end{array}$ \\
\hline & No more than $50 \mathrm{mSv}$ in any one year \\
\hline Lens of the eye & $150 \mathrm{mSv} /$ year \\
\hline Skin & $500 \mathrm{mSv} /$ year \\
\hline Hands and feet & $500 \mathrm{mSv} /$ year \\
\hline
\end{tabular}

Table 4. Annual permissible number of vertebroplasties

\begin{tabular}{lcc}
\hline & \multicolumn{2}{c}{ No. of procedures } \\
\cline { 2 - 3 } & Without Apron & With Apron \\
\hline Surgeon & 114 & 1,700 \\
Assistant surgeon & 8,500 & 34,000 \\
Nurse & 3,091 & 8,500 \\
Patient & \multicolumn{2}{c}{86} \\
\hline
\end{tabular}

to $1,056.42$. The average time per procedure was 297.5 seconds \pm 52.2 ranging from 205 to 350 . The mean emitted dose from the fluoroscope was $51.18 \mathrm{mSv} \pm 12.51$ ranging from 35.21 to 66.02 for a single thoracic $\mathrm{PVP}$ and $48.96 \mathrm{mSv} \pm 13.30$ ranging from 38.21 to 61.54 for a single lumbar PVP $(p=0.922)$. The mean duration was 355.2 seconds \pm 85.2 ranging from 280 to 420 for a single thoracic PVP and 278.86 seconds \pm 72.5 ranging from 160 to 420 for a single lumbar PVP $(p=0.097)$ (Table 1).

\section{Radiation Exposure}

Cumulative radiation doses for 17 PVPs at each location were as follows: $2.97 \pm 0.54 \mathrm{mSv}$, ranging 2.11 to $3.21 \mathrm{mSv}$ outside the surgeon's thyroid protector, $0.20 \pm 0.04 \mathrm{mSv}$, ranging 0.15 to $0.30 \mathrm{mSv}$ inside the apron at the surgeon's chest level, $0.04 \pm 0.11 \mathrm{mSv}$, ranging 0.02 to $0.14 \mathrm{mSv}$ outside the assistant surgeon's thyroid protector, $0.01 \pm 0.005$, ranging 0.005 to 0.03 $\mathrm{mSv}$ inside the apron at the assistant surgeon's chest level, and $0.11 \pm 0.02 \mathrm{mSv}$, ranging 0.08 to $0.15 \mathrm{mSv}$ outside the nurse's thyroid protector, $0.04 \pm 0.01 \mathrm{mSv}$, ranging 0.02 to $0.10 \mathrm{mSv}$ inside the apron at the nurse's chest level, and $3.97 \pm 0.52 \mathrm{mSv}$, ranging 3.44 to $4.12 \mathrm{mSv}$ at the patient's treatment area and $0.44 \pm 0.14 \mathrm{mSv}$, ranging 0.33 to $0.54 \mathrm{mSv}$ around the patient's head (Table 2, Fig. 2).

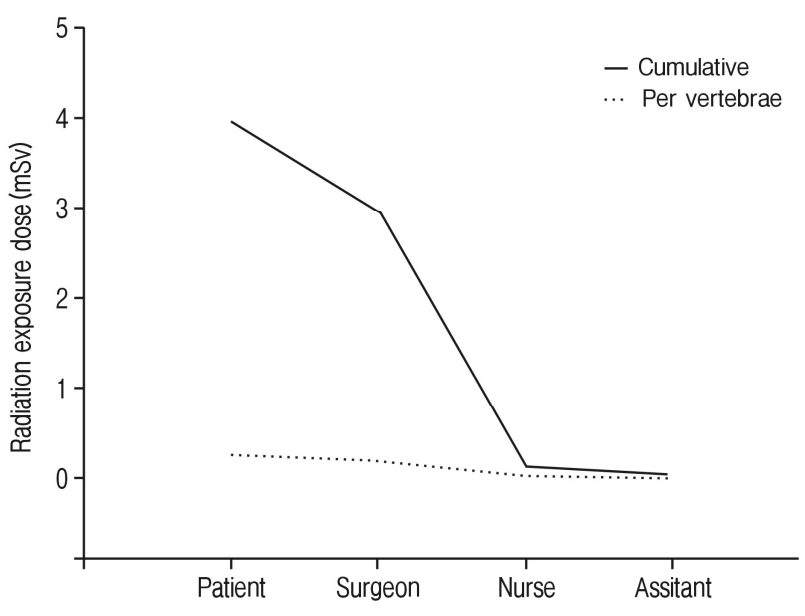

Fig. 2. Cumulative radiation exposure dose outside the medical personnel's thyroid protector and at the patient's treatment area for 17 consecutive vertebroplasty cases.

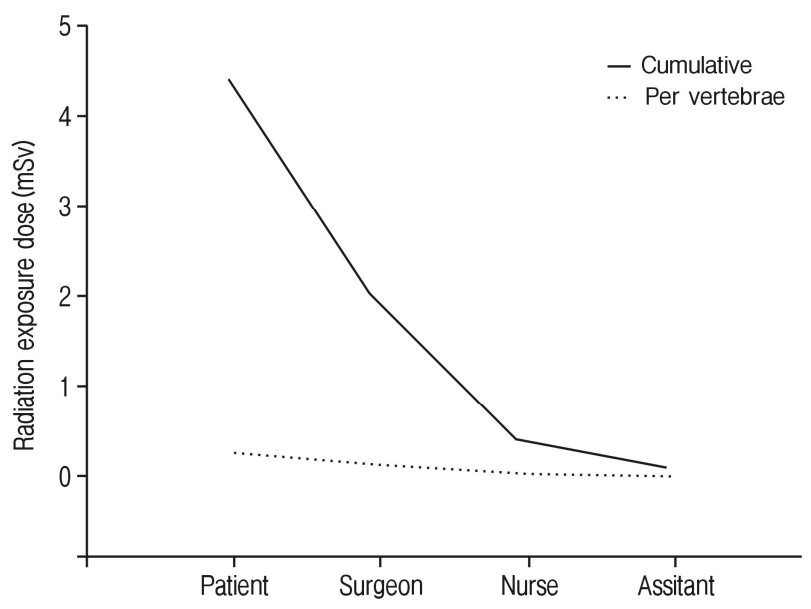

Fig. 3. Calculated radiation exposure dose during a single-level vertebroplasty inside the medical personnel's apron and at the patient's head.

The calculated mean dose for a single PVP at each location was as follows: $0.17 \mathrm{mSv} \pm 0.05$ ranging from 0.12 to 0.33 outside the surgeon's thyroid protector, $0.01 \mathrm{mSv} \pm 0.006$ ranging from 0.008 to 0.16 inside the apron at the surgeon's chest level, $2.4 \mu \mathrm{Sv} \pm 0.43$ ranging from 1.4 to 3.1 outside the assistant surgeon's thyroid protector, $0.6 \mu \mathrm{Sv} \pm 0.12$ ranging from 0.43 to 1.02 inside the apron at the assistant surgeon's chest level, 
$6.5 \mu \mathrm{Sv} \pm 1.3$ ranging from 3.3 to 8.5 outside the nurse's thyroid protector, $2.4 \mu \mathrm{Sv} \pm 0.4$ ranging from 1.6 to 2.7 inside the apron at the nurse's chest level, $0.23 \mathrm{mSv} \pm 0.01$ ranging from 0.20 to 0.30 at the patient's treatment area and $0.03 \mathrm{mSv} \pm 0.01$ ranging from 0.02 to 0.04 at the patient's head (Fig. 3).

\section{Annual Permissible Number of Vertebroplasties}

In planned exposure situations, the occupational radiation exposure limit is $20 \mathrm{mSv}$ per year, averaged over a five year period (100 mSv every five years) and the effective dose should not exceed $50 \mathrm{mSv}$ in any single year. The annual maximum target/organ permissible radiation dose is shown in Table 3. At this study, if an apron is not used the annual effective dose limit could be exceeded after performing 114 procedures. Table 4 shows the number of permitted annual radiation exposures.

\section{DISCUSSION}

Percutaneous vertebroplasty reduces pain and improves quality of life in patients with vertebral compression fractures and pathologic fractures ${ }^{4,5}$. Percutaneous vertebroplasty can be performed under local anesthesia with a low incidence of complications. However, during the procedure, medical personnel are exposed to radiation. Health care workers are exposed to more radiation than the general population. Therefore, when using radiation or radioactive materials, health care workers should recognize the importance of radiation protection.

Because hand and eye dosages were not measured separately, the measured dose outside of the thyroid protector represents the 'effective dose.' In the present study, the radiation dose does not meet the prescribed radiation dose limit. However, radiosensitivity can differ by tissue type 6 and different tissues may be exposed to different doses. For example, the operator's hand is exposed to the greatest amount of radiation during procedures $^{7-10)}$. Most previous studies were interested in radiation exposure to the patient and operator only. This study measured the radiation exposure dose to the nurse and assistant surgeon as well. Results show the total radiation exposure dose decreases as distance from the fluoroscope increases. In the present study, the radiation source was located on the ipsilateral side of the operator during vertebroplasty, so scattered radiation from the patient's skin may act as a secondary source of radiation.

If medical personnel perform more vertebroplasty procedures than permitted, cancer risk increases ${ }^{8}$. Radiation is cumulative during a person's lifetime and must be calculated as such. Percutaneous screw fixation or artificial disc replacement also require mobile $\mathrm{C}$-arm fluoroscopy and thus also expose medical personnel to radiation ${ }^{11,12)}$. Health care workers are exposed to more radiation than the average population, but most are unaware of the issue ${ }^{9)}$. Therefore there should be regulations in place limiting the number of surgeries each health care worker can perform that involve devices generating radiation, such as mobile $\mathrm{C}$-arm fluoroscopy. In addition, annual exposure levels should be restricted for people who are susceptible to radiation exposure even if the person is not the primary operator of the radiation device. Protection using lead gloves or shielding devices decreases the skin dose by more than $75 \% \%^{7,10}$. Aprons, lead glasses, thyroid protectors, and lead gloves must be used properly to minimize radiation exposure to medical personnel. The use of pulsed fluoroscopy mode also reduces radiation exposure $^{13,14)}$. Unless a precise image is required, the pulsed mode is recommended for mobile $\mathrm{C}$-arm fluoroscopy.

Because the study group in the present paper consisted of patients who only underwent percutaneous vertebroplasty, overall radiation exposure for individual medical personnel could not be estimated. The study period was not long enough to determine a long-term continuous exposure dose. In addition, hand and eye exposure were not investigated in this study.

\section{CONCLUSION}

The amount of radiation exposure is different among medical personnel in PVP. The major contributing factor is supposed to be the distance from a fluoroscope and the time of shooting $\mathrm{X}$-rays. In addition to wear proper X-ray protective gears, we can further minimize radiation exposure by reducing X-ray shooting time and standing aside from the fluoroscope. Taking recent guidelines into account, surgeons would exceed the extremity dose limits without protection at approximately 1,700 procedures per year

\section{- Acknowledgments}

This study was supported by a faculty research grant from Yonsei University College of Medicine for 2011 (6-2011-0163) and from the 2009 National Agenda Project (NAP) funded by the Korean Research Council of Fundamental Science \& Technology (P-09-JC-LU63-C01).

The authors would like to thank Dong-Su Jang, MFA, (Medical Illustrator) for his help with the illustrations.

\section{REFERENCES}

1. Cousins C, Sharp C: Medical interventional procedures-reducing the radiation risks. Clin Radiol 59(6):468-473, 2004

2. Galibert P, Deramond H, Rosat P, Le Gars D: [Preliminary note on the treatment of vertebral angioma by percutaneous acrylic vertebroplasty]. Neurochirurgie 33(2):166-168, 1987

3. Hargunani R, Le Corroller T, Khashoggi K, Murphy KJ, Munk PL: Percutaneous vertebral augmentation: the status of vertebroplasty and current controversies. Semin Musculoskelet Radiol 15(2):117-124, 2011

4. Amar AP, Larsen DW, Esnaashari N, Albuquerque FC, Lavine 
SD, Teitelbaum GP: Percutaneous transpedicular polymethylmethacrylate vertebroplasty for the treatment of spinal compression fractures. Neurosurgery 49(5):1105-1114, 2001; discussion 11141105

5. Chen KY, Ma HI, Chiang YH: Percutaneous transpedicular vertebroplasty with polymethyl methacrylate for pathological fracture of the spine. J Clin Neurosci 16(10):1300-1304, 2009

6. Biswas D, Bible JE, Bohan M, Simpson AK, Whang PG, Grauer JN: Radiation exposure from musculoskeletal computerized tomographic scans. J Bone Joint Surg Am 91(8):1882-1889, 2009

7. Synowitz M, Kiwit J: Surgeon's radiation exposure during percutaneous vertebroplasty. J Neurosurg Spine 4(2):106-109, 2006

8. Harstall R, Heini PF, Mini RL, Orler R: Radiation exposure to the surgeon during fluoroscopically assisted percutaneous vertebroplasty: a prospective study. Spine (Phila Pa 1976) 30(16): 1893-1898, 2005

9. Kruger R, Faciszewski T: Radiation dose reduction to medical staff during vertebroplasty: a review of techniques and methods to mitigate occupational dose. Spine (Phila Pa 1976) 28(14):1608-
1613, 2003

10. Fitousi NT, Efstathopoulos EP, Delis HB, Kottou S, Kelekis AD, Panayiotakis GS: Patient and staff dosimetry in vertebroplasty. Spine (Phila Pa 1976) 31(23):E884-889, 2006; discussioin E890.

11. Rampersaud YR, Foley KT, Shen AC, Williams S, Solomito M: Radiation exposure to the spine surgeon during fluoroscopically assisted pedicle screw insertion. Spine (Phila Pa 1976) 25(20): 2637-2645, 2000

12. Giordano BD, Baumhauer JF, Morgan TL, Rechtine GR. Cervical spine imaging using standard C-arm fluoroscopy: patient and surgeon exposure to ionizing radiation. Spine (Phila Pa 1976) 33(18): 1970-1976, 2008

13. Kotre CJ, Charlton S, Robson KJ, Birch IP, Willis SP, Thornley M: Application of low dose rate pulsed fluoroscopy in cardiac pacing and electrophysiology: patient dose and image quality implications. Br J Radiol 77(919):597-599, 2004

14. Cho JH, Kim JY, Kang JE, et al.: A Study to Compare the Radiation Absorbed Dose of the C-arm Fluoroscopic Modes. Korean J Pain 24(4):199-204, 2011 